Subscriber access provided by King Abdullah University of Science and Technology Library

\title{
Letter
}

\section{Ascorbic acid as a bifunctional hydrogen bond donor for the synthesis of cyclic carbonates from $\mathrm{CO}$ under ambient conditions}

Sunatda Arayachukiat, Chutima Kongtes, Alexander Barthel, Sai V. C. Vummaleti, Albert Poater, Sippakorn Wannakao, Luigi Cavallo, and Valerio D'Elia

ACS Sustainable Chem. Eng., Just Accepted Manuscript • DOI:

10.1021/acssuschemeng.7b01650 • Publication Date (Web): 14 Jul 2017

Downloaded from http://pubs.acs.org on July 18, 2017

\section{Just Accepted}

\begin{abstract}
"Just Accepted" manuscripts have been peer-reviewed and accepted for publication. They are posted online prior to technical editing, formatting for publication and author proofing. The American Chemical Society provides "Just Accepted" as a free service to the research community to expedite the dissemination of scientific material as soon as possible after acceptance. "Just Accepted" manuscripts appear in full in PDF format accompanied by an HTML abstract. "Just Accepted" manuscripts have been fully peer reviewed, but should not be considered the official version of record. They are accessible to all readers and citable by the Digital Object Identifier (DOI®). "Just Accepted" is an optional service offered to authors. Therefore, the "Just Accepted" Web site may not include all articles that will be published in the journal. After a manuscript is technically edited and formatted, it will be removed from the "Just Accepted" Web site and published as an ASAP article. Note that technical editing may introduce minor changes to the manuscript text and/or graphics which could affect content, and all legal disclaimers and ethical guidelines that apply to the journal pertain. ACS cannot be held responsible for errors or consequences arising from the use of information contained in these "Just Accepted" manuscripts.
\end{abstract}




\title{
Ascorbic acid as a bifunctional hydrogen bond donor for the synthe- sis of cyclic carbonates from $\mathrm{CO}_{2}$ under ambient conditions
}

\author{
Sunatda Arayachukiat, ${ }^{\mathrm{a}}{ }^{*}$ Chutima Kongtes, ${ }^{\mathrm{a}}{ }^{\star}$ Alexander Barthel, ${ }^{\mathrm{b}}$ Sai V. C. Vummaleti, ${ }^{\mathrm{b}}$ Albert \\ Poater, ${ }^{\mathrm{b}, \mathrm{c}}$ Sippakorn Wannakao, ${ }^{\mathrm{a}}$ Luigi Cavallo ${ }^{\mathrm{b}}$ and Valerio D’Elia ${ }^{\mathrm{a}, *}$ \\ ${ }^{\text {a }}$ Department of Materials Science and Engineering, School of Molecular Science and Engineering, Vidyasirimedhi Institute of Science \\ and Technology, (VISTEC), 21210, Payupnai, Wang Chan, Thailand, email: valerio.delia@ vistec.ac.th \\ ${ }^{\mathrm{b}}$ King Abdullah University of Science \& Technology, KAUST Catalysis Center (KCC), 23955-6900 Thuwal, Saudi Arabia. \\ ${ }^{\mathrm{c}}$ Institut de Química Computacional i Catàlisi and Departament de Química, Universitat de Girona, c/Maria Aurèlia Capmany 6, \\ 17003 Girona, Catalonia, Spain
}

KEYWORDS: $\mathrm{CO}_{2}$ fixation, cyclic carbonates, organocatalysis, bifunctional organocatalyst, ascorbic acid

\begin{abstract}
Readily available ascorbic acid was discovered as an environmentally benign hydrogen bond donor (HBD) for the synthesis of cyclic organic carbonates from $\mathrm{CO}_{2}$ and epoxides in the presence of nucleophilic co-catalysts. The ascorbic acid/TBAI (TBAI: tetrabutylammonium iodide) binary system could be applied for the cycloaddition of $\mathrm{CO}_{2}$ to various epoxides under ambient or mild conditions. DFT calculations and catalysis experiments revealed an intriguing bifunctional mechanism in the step of $\mathrm{CO}_{2}$ insertion involving different hydroxyl moieties (enediol, ethyldiol) of the ascorbic acid scaffold.
\end{abstract}

\section{Introduction}

Cyclic organic carbonates represent a relevant class of chemicals that find application in chemical processes as green solvents. ${ }^{1-3}$ They are also applied as key intermediates in Shell's Omega process for the production of glycols and in the AsahiKasei synthesis of polycarbonates. ${ }^{4-5,6}$ Recent advances have significantly expanded the portfolio of reactions employing cyclic carbonates as raw materials. ${ }^{7-12}$ As a viable and atom-efficient strategy for the chemical fixation of $\mathrm{CO}_{2}$ into commodity chemicals, ${ }^{13-15}$ the preparation of these compounds by the cycloaddition of $\mathrm{CO}_{2}$ to epoxides is currently in the spotlight of academic research. ${ }^{16-19}$ Various efforts have been directed to the development of catalytic systems able to function under ambient conditions in order to afford a more sustainable process that circumvents the high indirect carbon costs associated to an energy intensive ${ }^{6}$ conversion of $\mathrm{CO}_{2}{ }^{18,}{ }^{20}$ In the homogeneous phase, the cycloaddition reaction can take place under mild conditions when catalyzed by metal-organic complexes ${ }^{21-23}$ and coordination compounds; ${ }^{24-25}$ the reaction catalyzed by $\mathrm{YCl}_{3} / \mathrm{TBAB}$ (TBAB: tetrabutylammonium bromide) can take place, under ambient conditions, even when a flow of industrial flue gas is used as an impure source of $\mathrm{CO}_{2} \cdot{ }^{26}$ Despite these advances, the development of metal-free, inexpensive and readily available catalysts for the title reaction is regarded as highly desirable from the sustainability and economic standpoints. ${ }^{27-29}$

In this context, several active organocatalysts for the cycloaddition of $\mathrm{CO}_{2}$ to epoxides have been reported. These include ionic liquids, ${ }^{30-31} \mathrm{~N}$-heterocyclic carbenes $) \mathrm{NHCs}\left({ }^{32-33}\right.$ ammonium and phosphonium salts, ${ }^{34-35}$ nitrogen nucleophiles. ${ }^{36-37} \mathrm{Ad}-$ ditionally, a variety of molecules able to activate the epoxide substrate by the formation of )a network of( hydrogen bonds and that require the presence of a nucleophilic co-catalyst for the epoxide ring opening step has been reported..$^{38-39,40}$ Single and dual component catalytic systems displaying phenolic protons are popular hydrogen bond donors. ${ }^{41-45}$ Other active HBDs displaying hydroxyl groups include glycidol, ${ }^{46}$ polyalcoholic compounds, ${ }^{47-49}$ ammonium $^{50-51}$ or phosphonium-functionalized alcohols ${ }^{52}$ fluorinated alcohols ${ }^{53}$ hydroxyl-functionalized N-heterocycles, ${ }^{54-55}$ silanediols ${ }^{56}$ and boronic acids ${ }^{57}$ Remarkably, only a handful of these organocatalysts are reported to promote the title reaction under ambient conditions and the turnover frequencies obtained are generally very low (vide infra). ${ }^{35-}$ ${ }^{36,55-56}$ Moreover, there has been scarce attention to the toxicity and large-scale availability of the HBDs studied. Widely applied phenols, for instance, are highly toxic and potentially mutagenic compounds and therefore they lack of one of the main perks generally attributed to organocatalysts. ${ }^{58}$ other active organocatalysts are not readily available and require various preparative steps. Therefore, we target in this study the development of a non-toxic, commercially available and renewably sourced HBD able to function under ambient conditions. To this aim, the catalytic performance of various HBDs complying with such requisites was evaluated in the cycloaddition of $\mathrm{CO}_{2}$ to epoxides in the presence of a nucleophilic co-catalyst under ambient conditions. We were delighted to find that ascorbic acid/TBAI is an efficient organocatalytic pair for the synthesis of cyclic carbonates under ambient or very mild conditions. Additionally, intriguing mechanistic aspects relative to the structure-activity relationship of ascorbic acid are discussed with the support of DFT calculations. Despite ascorbic acid being often used in synthesis and catalysis as a stoichiometric reducing agent, ${ }^{59}$ we report in this study a unique application of this compound as a main catalytic component. 


\section{Results and Discussion}

In compliance with the targets set in the introduction, we selected for this study non-toxic and readily available HBDs. On the basis of the well-established catalytic activity of sugar alcohols, ${ }^{60}$ polyols, ${ }^{47-48}$ and carboxylic acids,${ }^{61}$ in the cycloaddition of $\mathrm{CO}_{2}$ to epoxides we selected lactic acid, glucose, erythritol and pentaerythritol as potential candidates. The latter compound was previously studied by Kühn, Cokoja et al. ${ }^{47}$ but not under ambient conditions. Additionally, we considered ascorbic acid that presents, besides the ethyldiol side chain, enediol hydroxy groups that have not been previously studied as hydrogen bonding moieties. An ascorbic acid derivative protected with an acetal group at its ethyldiol functionality (APAA: acetal protected ascorbic acid) was, as well, investigated. The selected HBDs were screened for catalytic activity using the cycloaddition of $\mathrm{CO}_{2}$ to epichlorhydrin (1a) as a benchmark reaction (Table 1). The reaction was carried out under ambient conditions (r.t., $\mathrm{CO}_{2}$ balloon) in the presence of TBAI as a nucleophilic cocatalyst.

Table 1. Screening of various hydrogen bond donors for the cycloaddition of $\mathrm{CO}_{2}$ to epichlorhydrin under ambient conditions in the presence of TBAI. ${ }^{a}$

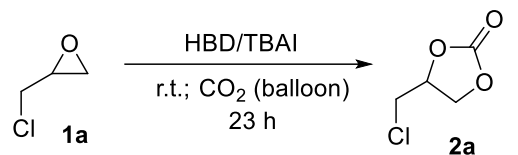

\begin{tabular}{|c|c|c|c|c|c|}
\hline Entry & $\begin{array}{l}\text { HBD or } \\
\text { Catalyst }\end{array}$ & $\begin{array}{l}\text { Conv. } \\
(\%)^{\mathrm{b}}\end{array}$ & $\begin{array}{l}\text { TON/ } \\
\text { TOF }\left(h^{-1}\right)\end{array}$ & $\begin{array}{l}\text { Commerci } \\
\text { al } \\
\text { Availabili } \\
\text { ty }(\mathrm{Y} / \mathrm{N})^{\mathrm{c}}\end{array}$ & Ref. \\
\hline 1 & $\begin{array}{l}\text { (L)-Ascorbic } \\
\text { acid }\end{array}$ & 70 & $35 / 1.5$ & $\mathrm{Y}$ & This work \\
\hline $2^{\mathrm{d}}$ & $\begin{array}{l}\text { (L)-Ascorbic } \\
\text { acid }\end{array}$ & $94(67)^{\mathrm{e}}$ & $\begin{array}{l}47 / 2 \\
(67 / 2.9)^{\mathrm{e}}\end{array}$ & $\mathrm{Y}$ & This work \\
\hline 3 & APAA & 58 & $29 / 1.3$ & $\mathrm{~N}$ & This work \\
\hline 4 & Lactic acid & 59 & $29.5 / 1.3$ & $\mathrm{Y}$ & This work \\
\hline 5 & (D)-Glucose & 45 & $27 / 1$ & $\mathrm{Y}$ & This work \\
\hline 6 & Erythritol & 54 & $27 / 1.2$ & $\mathrm{Y}$ & This work \\
\hline 7 & $\begin{array}{l}\text { Pentaerythrit } \\
\text { ol }\end{array}$ & 41 & $20.5 / 0.9$ & $\mathrm{Y}$ & This work \\
\hline 8 & $\begin{array}{l}2- \\
\text { Pyridinemeth } \\
\text { anol }\end{array}$ & 78 & $26 / 1.1^{\mathrm{f}}$ & $\mathrm{Y}$ & 55 \\
\hline 9 & $\begin{array}{l}\text { Dinaphthyl } \\
\text { Si-diol }\end{array}$ & 93 & $9.3 / 0.5^{f}$ & $\mathrm{~N}$ & 56 \\
\hline $10^{g}$ & $\begin{array}{l}\mathrm{DBU} / \mathrm{PhCH}_{2} \\
\mathrm{Br}\end{array}$ & 93 & $10.8 / 0.45^{\mathrm{f}}$ & $\mathrm{Y}$ & 36 \\
\hline $11^{\mathrm{d}}$ & $\begin{array}{l}\text { Tetraethylen } \\
\text { e glycol/KI }\end{array}$ & 92 & $9.2 / 0.38^{f}$ & $\mathrm{Y}$ & 48 \\
\hline 12 & $\begin{array}{l}\text { P-ylide- } \mathrm{CO}_{2}- \\
\text { adduct }\end{array}$ & 90 & $18 / 3^{\mathrm{f}}$ & $\mathrm{N}$ & 35 \\
\hline 13 & TBAI & 31 & $15.5 / 0.67$ & $\mathrm{Y}$ & This work \\
\hline
\end{tabular}

a Reactions conditions: epichlorhydrin (25 mmol), HBD 0.5 mmol ( $2 \mathrm{~mol} \%)$ and nucleophile $1 \mathrm{mmol}(4 \mathrm{~mol} \%)$, r.t., 1 bar $\mathrm{CO}_{2}$ (balloon), $23 \mathrm{~h} .{ }^{\mathrm{b}}$ Determined by ${ }^{1} \mathrm{H}$ NMR (See the ESI file). ${ }^{\mathrm{c}} \mathrm{Re}-$ fers to the availability of HBD from commercial sources (Y: available; N: not available). ${ }^{\mathrm{d}}$ At $40{ }^{\circ} \mathrm{C}$. ${ }^{\mathrm{e}}$ At $40{ }^{\circ} \mathrm{C}$ and using ascorbic acid $(1 \mathrm{~mol} \%)$ and TBAI $(2 \mathrm{~mol} \%) .{ }^{\mathrm{f}}$ Calculated on the basis of published data. ${ }^{\mathrm{g}}$ Using styrene oxide as a substrate. TON: turnover number; TOF: turnover frequency (TOF: TON/reaction time (h)).

The HBDs investigated in this study displayed moderate to high catalytic activity in the benchmark reaction that was, in all cases, higher than that observed when using only TBAI in a blank reaction (Table 1, entry 13). By analysis of the data presented in Table 1, we were delighted to find that ascorbic acid, an off-the-shelf, non-toxic and inexpensive chemical, is able to offer a good degree of conversion of epoxide 1a under ambient conditions (Table 1, Entry 1) that became nearly quantitative by increasing the reaction temperature to just $40^{\circ} \mathrm{C}$ (Table 1, Entry 2 ). At this temperature, the catalytic loading of ascorbic acid could be reduced to just 1 mol\% obtaining a TON of 67 (TOF: $\left.2.9 \mathrm{~h}^{-1}\right)$. Interestingly, ascorbic acid is a naturally occurring compound that can be produced in large scale via sustainable feedstocks and processes. ${ }^{62}$ The ethyldiol-protected ascorbic acid derivative APAA displayed a lower catalytic activity than the pristine ascorbic acid molecule (Table 1, Entry 3). This effect can be tentatively ascribed to the suppression of the hydrogen bonding capability of the alcoholic protons of the side chain and it is investigated later in the text. Entries 8-12 in Table 1 refer to literature reported organocatalytic systems employed under ambient conditions that are displayed for comparison purposes. It is possible to observe that ascorbic acid displays TON values that are higher than any other organocatalytic system applied under comparable reaction conditions (Table 1, Entries 812). In terms of TOF, it is possible to observe that the values calculated for the literature reported HBDs and other organocatalytic systems are generally just a fraction of what observed for ascorbic acid (Table 1, Entries 8-11). The TOF of ascorbic acid is second only to the phosphorous-ylide- $\mathrm{CO}_{2}$ adduct reported by Zhou et al. (Table 1, Entry 12). ${ }^{33}$ However, the latter is neither a green (given the high toxicity of triphenylphosphine) or a readily available compound as it needs to be prepared by the reaction of a phosphonium salt with butyllithium followed by reaction with $\mathrm{CO}_{2}{ }^{33}$

Other nucleophilic co-catalysts were studied as an alternative to TBAI (See Table S2 in the supporting information) that, however, resulted as the most active co-catalyst. Importantly, the addition of relatively large amounts of water to the reaction environment (up to $10 \mathrm{~mol} \%$, See Figure 1) led to no or only marginal decrease of the catalytic activity of ascorbic acid/TBAI thus highlighting the potential resilience of this catalytic system to presence of moisture as a common pollutant in waste $\mathrm{CO}_{2}$.

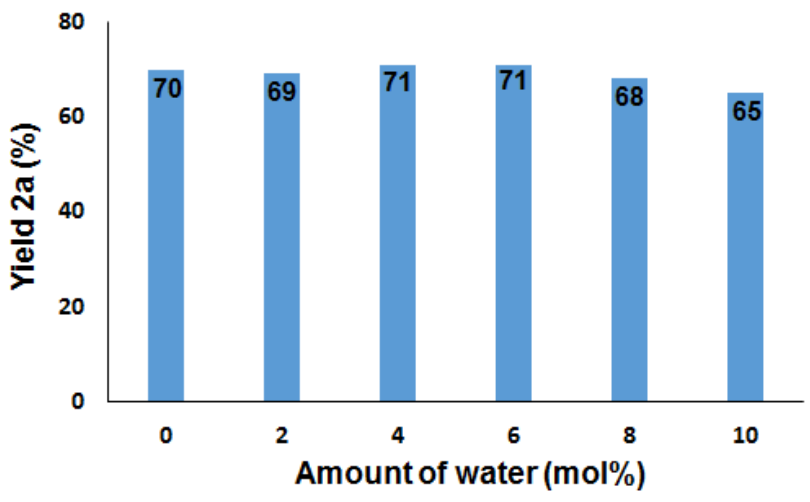

Figure 1. Catalytic performance of ascorbic acid (2 mol\%) and TBAI (4 mol\%) in the cycloaddition of $\mathrm{CO}_{2}$ to epichlorhydrin in the presence of increasing amounts water at r.t., 1 bar $\mathrm{CO}_{2}$ (balloon), $23 \mathrm{~h}$.

We explored the substrate scope of ascorbic acid/TBAI for the cycloaddition of $\mathrm{CO}_{2}$ to several epoxides (1a-1g; Table 2). The reactions were carried out under ambient or mild conditions 
and the target carbonates were always formed selectively (See the NMR spectra in Section S4 of the SI). An increase of the catalyst loading to $4 \mathrm{~mol} \%$ ascorbic acid and $8 \mathrm{~mol} \%$ TBAI under ambient conditions led to a slight increase of carbonate $\mathbf{2 a}$ yield (Table 2, Entries 1 and 2). Under these reaction conditions sterically unhindered epoxides $\mathbf{1 b}$-1d could be converted to the corresponding carbonate in good to nearly quantitative yields (Table 2, Entries 5, 7, 8). An increase of the $\mathrm{CO}_{2}$ pressure to 5 bar at room temperature led as well to a moderate increase of cyclic carbonate yields (Table 2, Entries 3 and 6). The reactions under ambient conditions afforded generally lower yields when epoxides with larger side chains such as 1-hexene oxide (1e) or styrene oxide (1f) were employed. Therefore, the cycloaddition of $\mathrm{CO}_{2}$ to these substrates was successfully carried out under ambient pressure but at $60{ }^{\circ} \mathrm{C}$ using just 1 to $2 \mathrm{~mol} \%$ of ascorbic acid (Table 2, Entries 9, 10). Moreover, internal epoxide 1g could be transformed into the corresponding carbonate under relatively mild conditions $\left(100{ }^{\circ} \mathrm{C} ; 20\right.$ bar, Table 2, Entry 11).

Table 2. Cycloaddition of $\mathrm{CO}_{2}$ to various epoxides catalyzed by ascorbic acid/TBAI. ${ }^{a}$

\begin{tabular}{|c|c|c|c|c|c|c|c|}
\hline & $\mathrm{R}_{1 \mathrm{a}-1}$ & & & $\begin{array}{r}\text { Ascorbic } \\
\text { TBAI } \\
\mathrm{CO}_{2} \\
23 \mathrm{~h}\end{array}$ & $\mathrm{R}_{1}$ & $\int_{0}^{0}$ & \\
\hline Entry & $\mathrm{R}_{1}, \mathrm{R}_{2}$ & & & $\begin{array}{l}\text { mperature } \\
\text { C) }\end{array}$ & $\begin{array}{l}\text { Pressure } \\
\text { (bar) }\end{array}$ & $\begin{array}{l}\text { Ascorbic } \\
\text { acid, TBAI } \\
\text { loading } \\
(\operatorname{mol} \%)\end{array}$ & $\begin{array}{l}\text { Yield } \\
(\%)\end{array}$ \\
\hline 1 & $\mathrm{CH}_{2} \mathrm{Cl}, \mathrm{H}(\mathbf{1 a})$ & & r.t & & 1 & 2,4 & 70 \\
\hline 2 & & & r.t & & 1 & 4,8 & 84 \\
\hline 3 & & & r.t. & & 5 & 2,4 & 77 \\
\hline 4 & & & 40 & & 1 & 2,4 & 94 \\
\hline 5 & Me, H (1b) & & r.t. & & 1 & 4,8 & 64 \\
\hline 6 & & & r.t. & & 5 & 2,4 & 82 \\
\hline 7 & $\begin{array}{l}\mathrm{CH}_{2}=\mathrm{CH}_{2} \\
\text { (1c) }\end{array}$ & $\mathrm{H}$ & r.t. & & 1 & 4,8 & 97 \\
\hline 8 & Et, H (1d) & & r.t & & 1 & 4,8 & 81 \\
\hline 9 & $\mathrm{Bu}, \mathrm{H}(\mathbf{1 e})$ & & 60 & & 1 & 1,2 & 86 \\
\hline 10 & $\mathrm{Ph}, \mathrm{H}(\mathbf{1 f})$ & & 60 & & 1 & 2,4 & 96 \\
\hline 11 & $-\left(\mathrm{CH}_{2}\right)_{4^{-}}(\mathbf{l g})$ & & 100 & & 20 & 2,4 & 88 \\
\hline
\end{tabular}

${ }^{a}$ All reactions were carried out using epoxides $1 \mathbf{a}-\mathbf{1 g}(25 \mathrm{mmol})$ for $23 \mathrm{~h}$ according to the conditions specified in the table; the reactions involving a $\mathrm{CO}_{2}$ pressure higher than 1 bar were carried out in a stainless steel autoclave.

${ }^{1} \mathrm{H}$ NMR is a useful tool to investigate the interaction between the HBD and the epoxide by monitoring the variation of the chemical shift of the hydrogen bonding moieties and of the substrate protons. ${ }^{40,46,55}$ In the case of ascorbic acid, being insoluble in most common organic solvents, this study was carried out in DMSO-d6 (See Section 5 of the SI). When the ${ }^{1} \mathrm{H}$ NMR spectra of solutions of epichlorhydrin and ascorbic acid were collected, the acidic enediol protons of ascorbic acid provided broad signals and very limited shifts with respect to the corresponding positions in the ${ }^{1} \mathrm{H}$ NMR of the pure substance (Figure S13, Table S3). Nevertheless, for the signals relative to the epichlorhydrin protons, a progressive upfield shift was noticed when increasing the ascorbic acid/epichlorhydrin molar ratio (Figure S12, Table S3). Interestingly, the extent of the shifts with respect to the ${ }^{1} \mathrm{H}$ NMR of pure epichlorhydrin is linearly correlated to the excess of ascorbic acid employed (Figure S14) highlighting a specific interaction between the HBD and the substrate even in this highly polar medium. A comparable, but larger, upfield shift of the protons of glycidol upon interaction with a HBD (in the specific case another molecule of glycidol) has been observed by Capacchione et al. ${ }^{46}$

In order to achieve deeper insight into the mechanism ${ }^{63-64}$ of the ascorbic acid catalyzed cycloaddition reaction we performed density functional theory (DFT) calculations at the GGA B3LYP level (See section S9 of the ESI files for further details) using epoxide $\mathbf{1 b}$ (propylene oxide, PO) as a substrate. Figure $2 \mathrm{a}$ presents the computed free energy surface for the cycloaddition of $\mathrm{PO}$ and $\mathrm{CO}_{2}$ catalyzed by ascorbic acid in the presence of TBAI along with the structure of intermediates and transition states. Coordination of PO to ascorbic acid takes place via a hydrogen bond between the two enediolic hydroxyl protons and the oxygen atom of the epoxide ring. PO coordination is calculated to be slightly endergonic and leads to intermediate $\mathbf{A}$ that lies $0.8 \mathrm{kcal} / \mathrm{mol}$ above ascorbic acid. From a structural point of view, in $\mathbf{A}$, the presence of strong hydrogen bond interactions results in the activation of the epoxide with the two $\mathrm{C}-\mathrm{O}$ bond lengths extended from 1.438 and $1.439 \AA$ to 1.452 and $1.460 \AA$ respectively. The next step corresponds to the opening of the epoxide ring by the iodine anion, leading to the formation of intermediate $\mathbf{B}$, isoenergetic with respect to the starting species ascorbic acid. This step proceeds through transition state TS-AB and requires overcoming an overall barrier of $13.0 \mathrm{kcal} / \mathrm{mol}$ above ascorbic acid. The insertion of $\mathrm{CO}_{2}$ in $\mathbf{B}$ leads to the formation of the hemicarbonate intermediate $\mathbf{C}$, which lies $3.4 \mathrm{kcal} / \mathrm{mol}$ above ascorbic acid. The $\mathrm{CO}_{2}$ insertion step requires the overcoming of a barrier (TS-BC) located 12.4 $\mathrm{kcal} / \mathrm{mol}$ above ascorbic acid. From a structural point of view, transition state TS-BC displays a stabilizing hydrogen bond interaction between the hydrogen atom of the secondary alcohol moiety of the side chain and an oxygen atom of the $\mathrm{CO}_{2}$ molecule (See Figure 2b). Next, starting from intermediate $\mathbf{C}$, we studied the ring closure step leading to the formation of the desired cyclic carbonate product coordinated to ascorbic acid via intermediate D. Ring closure is predicted to be the rate-determining step, with a barrier of $15.6 \mathrm{kcal} / \mathrm{mol}$ (TS-CD) relative to ascorbic acid.

Overall, for the reaction mechanism of ascorbic acid, the calculated barriers range from $12.0 \mathrm{kcal} / \mathrm{mol}$ to $16.0 \mathrm{kcal} / \mathrm{mol}$, which are consistent with the observed activity at room temperature. For comparison, we calculated the cycloaddition reaction mechanism for the acetal protected ascorbic acid derivative (APAA). The corresponding energy profile is presented in Figure $2 \mathrm{~d}$. The main results can be summarized in the following points: 1) The calculated ring opening barrier (TS-AB') for APAA is $3.2 \mathrm{kcal} / \mathrm{mol}$ higher in energy than the corresponding barrier for ascorbic acid $(16.2 \mathrm{kcal} / \mathrm{mol} \mathrm{vs} 13.0 \mathrm{kcal} / \mathrm{mol}$, respectively); 2) The calculated $\mathrm{CO}_{2}$ insertion barrier (TS-BC', Figure 2c) for APAA is significantly higher in energy (by 5.5 $\mathrm{kcal} / \mathrm{mol}$ ) when compared to the corresponding barrier for ascorbic acid. These observations can be partly attributed to the acetal protecting group acting as an electron donor and influencing the hydrogen bonding ability of APAA. For instance, the $\mathrm{H}$-bonds to the opened epoxide arising from the enediolic hydroxyls in TS-BC (1.546 and $1.722 \AA$ ) are slightly shorter than for TS-BC' (1.621 and $1.763 \AA$ ). More importantly, the transition states relative to ascorbic acid display several additional stabilizing intramolecular hydrogen bonds that are not available 
for APAA. For instance, beside the stronger $\mathrm{H}$-bond between $\mathrm{CO}_{2}$ and an ethyldiol hydroxyl in TS-BC $(2.076 \AA)$, there are $\mathrm{H}$-bonds between the ethyldiol hydroxyls in ascorbic acid (2.311 $\AA$ for TS-AB and $2.234 \AA$ for TS-BC) that are absent for the analogous transition states of APAA (for TS-AB and TSAB see $\quad$ Figure $\quad$ S15).
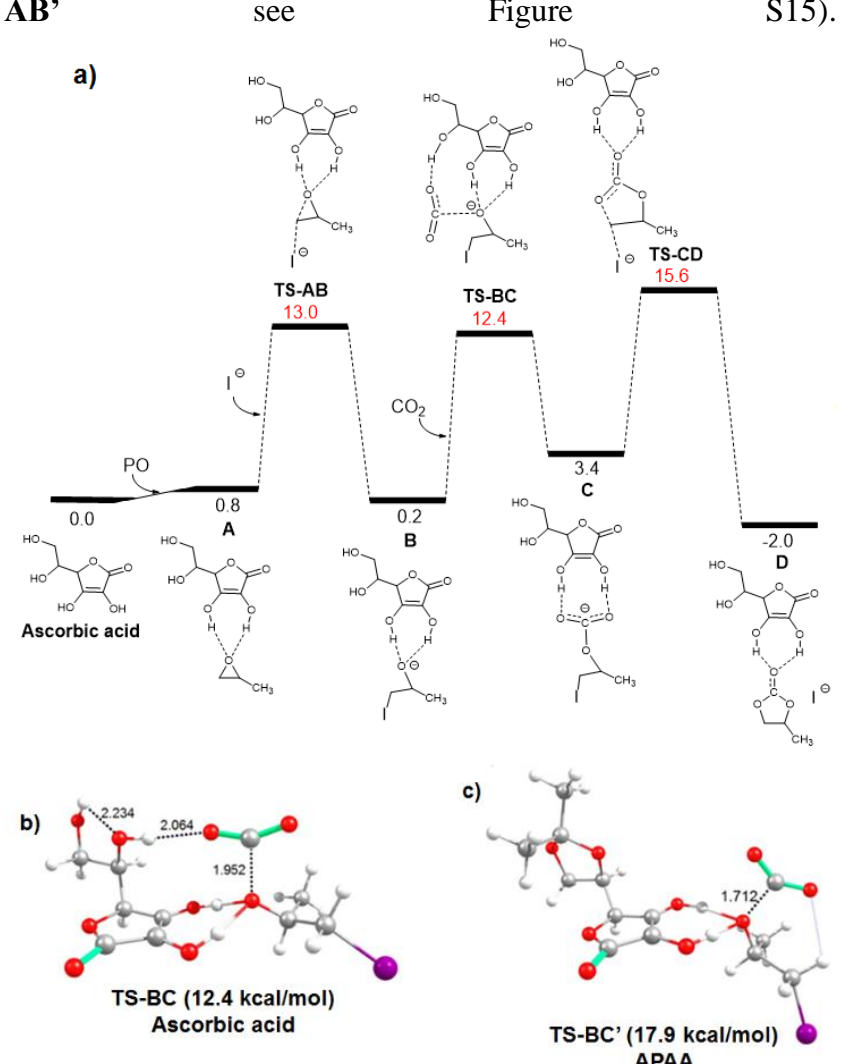

d)

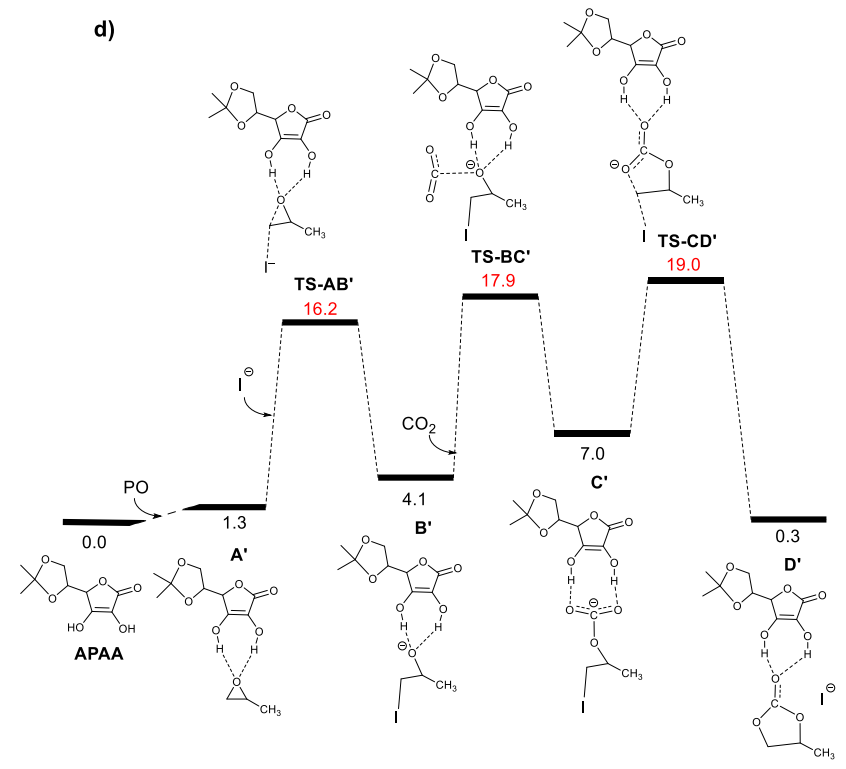

Figure 2. a) Computed free energy surface for the cycloaddition of $\mathrm{CO}_{2}$ to $\mathrm{PO}$ catalyzed by ascorbic acid. Free energies in solution (PO as the solvent) are given in $\mathrm{kcal} / \mathrm{mol}$ relative to the starting point. The values in red represent the energies of the transition states. b) Geometries of the $\mathrm{CO}_{2}$ insertion transition states, TS-BC, for ascorbic acid and (c) TS-BC' for the APAA derivative. d) Computed free energy surface for the cycloaddition of $\mathrm{CO}_{2}$ to $\mathrm{PO}$ catalyzed by APAA. Selected distances are given in $\AA$.
3) Similar to ascorbic acid, the ring closure step is predicted to be the rate-determining step; however, the calculated barrier (TS-CD') for APAA is $3.4 \mathrm{kcal} / \mathrm{mol}$ higher in energy than the corresponding barrier for ascorbic acid.

Overall, these results suggest that the bifunctional activation of $\mathrm{CO}_{2}$ by the different moieties of ascorbic acid is important to lower the barrier for the step of $\mathrm{CO}_{2}$ insertion. Moreover, the APAA catalyzed cycloaddition between propylene oxide and $\mathrm{CO}_{2}$ is less favorable both from a kinetic and thermodynamic standpoint when compared to the case of ascorbic acid. This observation is in good agreement with the experimental results in Table 1.

\section{Conclusions}

Ascorbic acid was discovered as an environmentally friendly and efficient off-the-shelf hydrogen bond donor for the cycloaddition of $\mathrm{CO}_{2}$ to various epoxides under ambient or very mild conditions. It represents a unique organocatalyst for this transformation that is at the same time non-toxic, renewably sourced readily available and active under ambient conditions. DFT calculations were able to show the cooperative role of the hydroxyl groups of the enediol and ethyldiol moieties for lowering the activation barrier of $\mathrm{CO}_{2}$. In these regards, ascorbic acid can be considered as a bifunctional organocatalyst for the cycloaddition of $\mathrm{CO}_{2}$ to epoxides. Given its observed activity and chiral structure, ascorbic acid, a thus far neglected but readily available and sustainable hydrogen bond donor, appears as a promising new entry for future application as a green organocatalyst in various examples of Brønsted acid catalyzed reactions. ${ }^{65}$

\section{ASSOCIATED CONTENT}

The Supporting Information is available free of charge on the ACS Publications website at DOI: XXXXXX. It includes general information, experimental procedures for the catalysis experiments, NMR studies and spectra of the reaction products, additional catalysis results and computational details, including Cartesian coordinates and absolute energies of all computed species (XYZ).

\section{AUTHOR INFORMATION}

\section{Corresponding Author}

*E-mail: valerio.delia@vistec.ac.th

ORCID

Valerio D' Elia: 0000-0002-5881-2496

Albert Poater: 0000-0002-8997-2599

Luigi Cavallo: 0000-0002-1398-338X

Notes

The authors declare no competing financial interest.

\section{Author Contributions}

The manuscript was written through contributions of all authors. All authors have given approval to the final version of the manuscript. $\$$ These authors contributed equally.

\section{Funding Sources}

A.P. thanks the Spanish MINECO for the project CTQ2014-59832JIN. V.D.E. thanks the Thailand Research Fund (Grant No. RSA6080059) for funding this research.

\section{ACKNOWLEDGMENT}


This publication is based upon work supported by the King Abdullah University of Science and Technology (KAUST). S.A. acknowledges financial support through postdoctoral fellowship from the Vidyasirimedhi Institute of Science and Technology.

\section{REFERENCES}

1. Schäffner, B.; Schäffner, F.; Verevkin, S. P.; Börner, A. Organic carbonates as solvents in synthesis and catalysis. Chem. Rev. 2010, 110, 4554-4581, DOI: 10.1021/cr900393d.

2. Lawrenson, S.; North, M.; Peigneguy, F.; Routledge, A. Greener solvents for solid-phase synthesis. Green Chem. 2017, 19, 952-962, DOI: $10.1039 / \mathrm{C} 7 \mathrm{GC} 00247 \mathrm{E}$.

3. Sathish, M.; Sreeram, K. J.; Raghava Rao, J.; Unni Nair, B. Cyclic Carbonate: A Recyclable Medium for Zero Discharge Tanning. ACS Sustainable Chem. Eng. 2016, 4, 1032-1040, DOI: 10.1021/acssuschemeng.5b01121.

4. Han, Z.; Rong, L.; Wu, J.; Zhang, L.; Wang, Z.; Ding, K. Catalytic hydrogenation of cyclic carbonates: a practical approach from $\mathrm{CO}_{2}$ and epoxides to methanol and diols. Angew. Chem., Int. Ed. 2012, 51,13041-13045, DOI: 10.1002/anie.201207781.

5. Van, M. H. J.; Veenstra, P. Process for the preparation of alkylene glycol. WO 2009/071651 A1, 11 June 2009.

6. Fukuoka, S.; Kawamura, M.; Komiya, K.; Tojo, M.; Hachiya, H.; Hasegawa, K.; Aminaka, M.; Okamoto, H.; Fukawa, I.; Konno, S. A novel non-phosgene polycarbonate production process using by-product $\mathrm{CO}_{2}$ as starting material. Green Chem. 2003, 5, 497507, DOI: 10.1039/B304963A.

7. Laserna, V.; Fiorani, G.; Whiteoak, C. J.; Martin, E.; Escudero-Adán, E.; Kleij, A. W. Carbon Dioxide as a Protecting Group: Highly Efficient and Selective Catalytic Access to Cyclic cis-Diol Scaffolds. Angew. Chem., Int. Ed. 2014, 53, 10416-10419, DOI: 10.1002/anie.201406645.

8. Beattie, C.; North, M.; Villuendas, P.; Young, C. Influence of temperature and pressure on cyclic carbonate synthesis catalyzed by bimetallic aluminum complexes and application to overall syn-bis-hydroxylation of alkenes. J. Org. Chem. 2013, 78, 419-426, DOI: 10.1021/jo302317w.

9. Kim, S. H.; Hong, S. H. Transfer hydrogenation of organic formates and cyclic carbonates: an alternative route to methanol from carbon dioxide. ACS Catal. 2014, 4, 3630-3636, DOI: $10.1021 / \mathrm{cs} 501133 \mathrm{~m}$

10. Khan, A.; Yang, L.; Xu, J.; Jin, L. Y.; Zhang, Y. J. Palladium-Catalyzed Asymmetric Decarboxylative Cycloaddition of Vinylethylene Carbonates with Michael Acceptors: Construction of Vicinal Quaternary Stereocenters. Angew. Chem., Int. Ed. 2014, 53, $11257-$ 11260, DOI: 10.1002/anie.201407013.

11. Liu, H.; Huang, Z.; Han, Z.; Ding, K.; Liu, H.; Xia, C.; Chen, $\mathrm{J}$. Efficient production of methanol and diols via the hydrogenation of cyclic carbonates using copper-silica nanocomposite catalysts. Green Chem. 2015, 17, 4281-4290, DOI: 10.1039/C5GC00810G.

12. Guo, W.; Gónzalez-Fabra, J.; Bandeira, N. A. G.; Bo, C.; Kleij, A. W. A Metal-Free Synthesis of N-Aryl Carbamates under Ambient Conditions. Angew. Chem., Int. Ed. 2015, 54, 11686-11690, DOI: 10.1002/anie.201504956.

13. Centi, G.; Quadrelli, E. A.; Perathoner, S. Catalysis for CO 2 conversion: a key technology for rapid introduction of renewable energy in the value chain of chemical industries. Energy Environ. Sci. 2013, 6, 1711-1731, DOI: 10.1039/C3EE00056G.

14. Aresta, M.; Dibenedetto, A.; Angelini, A. Catalysis for the valorization of exhaust carbon: from $\mathrm{CO}_{2}$ to chemicals, materials, and fuels. Technological use of $\mathrm{CO}_{2}$. Chem. Rev. 2013, 114, 1709-1742. DOI: $10.1021 / \mathrm{cr} 4002758$

15. Lee, S. T.; Ghani, A. A.; D'Elia, V.; Cokoja, M.; Herrmann, W. A.; Basset, J.-M.; Kühn, F. E. Liberation of methyl acrylate from metallalactone complexes via $\mathrm{M}-\mathrm{O}$ ring opening $(\mathrm{M}=\mathrm{Ni}, \mathrm{Pd})$ with methylation agents. New J. Chem. 2013, 37, 3512-3517, DOI: 10.1039/C3NJ00693J.
16. D'Elia, V.; Pelletier, J. D.; Basset, J. M. Cycloadditions to Epoxides Catalyzed by Group III-V Transition-Metal Complexes. ChemCatChem 2015, 7, 1906-1917, DOI: 10.1002/cctc.201500231.

17. Comerford, J. W.; Ingram, I. D.; North, M.; Wu, X. Sustainable metal-based catalysts for the synthesis of cyclic carbonates containing five-membered rings. Green Chem. 2015, 17, 1966-1987, DOI: 10.1039/C4GC01719F.

18. Martín, C.; Fiorani, G.; Kleij, A. W. Recent Advances in the Catalytic Preparation of Cyclic Organic Carbonates. ACS Catal. 2015, 5, 1353-1370, DOI: 10.1021/cs5018997.

19. Song, Q.-W.; Zhou, Z.-H.; He, L.-N. Efficient, selective and sustainable catalysis of carbon dioxide. Green Chem. 2017, DOI: 10.1039/C7GC00199A

20. von der Assen, N.; Jung, J.; Bardow, A. Life-cycle assessment of carbon dioxide capture and utilization: avoiding the pitfalls. Energy Environ. Sci. 2013, 6, 2721-2734, DOI: 10.1039/C3EE41151F.

21. Ma, R.; He, L.-N.; Zhou, Y.-B. An efficient and recyclable tetraoxo-coordinated zinc catalyst for the cycloaddition of epoxides with carbon dioxide at atmospheric pressure. Green Chem. 2016, 18, 226-231, DOI: 10.1039/C5GC01826A

22. Whiteoak, C. J.; Martin, E.; Belmonte, M. M.; Benet-Buchholz, J.; Kleij, A. W. An Efficient Iron Catalyst for the Synthesis of Five-and Six-Membered Organic Carbonates under Mild Conditions. Adv. Synth. Catal. 2012, 354, 469-476, DOI: 10.1002/adsc.201100752.

23. Castro-Osma, J. A.; Lamb, K. J.; North, M. Cr (salophen) Complex Catalyzed Cyclic Carbonate Synthesis at Ambient Temperature And Pressure. ACS Catal. 2016, 6, 5012-5025, DOI: 10.1021/acscatal.6b01386.

24. Monassier, A.; D'Elia, V.; Cokoja, M.; Dong, H.; Pelletier, J. D.; Basset, J. M.; Kühn, F. E. Synthesis of Cyclic Carbonates from Epoxides and $\mathrm{CO}_{2}$ under Mild Conditions Using a Simple, Highly Efficient Niobium-Based Catalyst. ChemCatChem 2013, 5, 1321-1324, DOI: $10.1002 /$ cctc. 201200916 .

25. Dutta, B.; Sofack-Kreutzer, J.; Ghani, A. A.; D'Elia, V.; Pelletier, J. D.; Cokoja, M.; Kühn, F. E.; Basset, J.-M. Nucleophiledirected selectivity towards linear carbonates in the niobium pentaethoxide-catalysed cycloaddition of $\mathrm{CO}_{2}$ and propylene oxide. Catal. Sci. Technol. 2014, 4, 1534-1538, DOI: 10.1039/C4CY00003J.

26. Barthel, A.; Saih, Y.; Gimenez, M.; Pelletier, J. D.; Kühn, F. E.; D'Elia, V.; Basset, J.-M. Highly integrated $\mathrm{CO}_{2}$ capture and conversion: direct synthesis of cyclic carbonates from industrial flue gas. Green Chem. 2016, 18, 3116-3123, DOI: 10.1039/c5gc03007b.

27. Fiorani, G.; Guo, W.; Kleij, A. W. Sustainable conversion of carbon dioxide: the advent of organocatalysis. Green Chem. 2015, 17, 1375-1389, DOI: 10.1039/C4GC01959H.

28. Cokoja, M.; Wilhelm, M. E.; Anthofer, M. H.; Herrmann, W. A.; Kühn, F. E. Synthesis of cyclic carbonates from epoxides and carbon dioxide by using organocatalysts. ChemSusChem 2015, 8, 2436-2454, DOI: $10.1002 / \mathrm{cssc} .201500161$.

29. Alves, M.; Grignard, B.; Mereau, R.; Jerome, C.; Tassaing, T.; Detrembleur, C. Organocatalyzed coupling of carbon dioxide with epoxides for the synthesis of cyclic carbonates: catalyst design and mechanistic studies. Catal. Sci. Technol. 2017, 7, 2651-2684, DOI: 10.1039/C7CY00438A.

30. Anthofer, M. H.; Wilhelm, M. E.; Cokoja, M.; Markovits, I. I.; Pöthig, A.; Mink, J.; Herrmann, W. A.; Kühn, F. E. Cycloaddition of $\mathrm{CO}_{2}$ and epoxides catalyzed by imidazolium bromides under mild conditions: influence of the cation on catalyst activity. Catal. Sci. Technol. 2014, 4, 1749-1758, DOI: 10.1039/C3CY01024D.

31. Zhang, Z.; Fan, F.; Xing, H.; Yang, Q.; Bao, Z.; Ren, Q. Efficient Synthesis of Cyclic Carbonates from Atmospheric $\mathrm{CO}_{2}$ Using a Positive Charge Delocalized Ionic Liquid Catalyst. ACS Sustainable Chem. Eng. 2017, 5, 2841-2846, DOI 10.1021/acssuschemeng.7b00513.

32. Kayaki, Y.; Yamamoto, M.; Ikariya, T., N-Heterocyclic Carbenes as Efficient Organocatalysts for $\mathrm{CO}_{2}$ Fixation Reactions. Angew. Chem., Int. Ed. 2009, 48, 4194-4197, DOI: 10.1002/anie.200901399. 
33. Wang, Y.-B.; Sun, D.-S.; Zhou, H.; Zhang, W.-Z.; Lu, X.-B. $\mathrm{CO}_{2}, \mathrm{COS}$ and $\mathrm{CS}_{2}$ adducts of N-heterocyclic olefins and their application as organocatalysts for carbon dioxide fixation. Green Chem. 2015, 17, 4009-4015, DOI: 10.1039/C5GC00948K

34. Ema, T.; Fukuhara, K.; Sakai, T.; Ohbo, M.; Bai, F.-Q.; Hasegawa, J.-Y. Quaternary ammonium hydroxide as a metal-free and halogen-free catalyst for the synthesis of cyclic carbonates from epoxides and carbon dioxide. Catal. Sci. Technol. 2015, 5, 2314-2321, DOI: 10.1039/C5CY00020C.

35. Zhou, H.; Wang, G.-X.; Zhang, W.-Z.; Lu, X.-B., $\mathrm{CO}_{2}$ Adducts of Phosphorus Ylides: Highly Active Organocatalysts for Carbon Dioxide Transformation. ACS Catal. 2015, 5, 6773-6779, DOI: 10.1021/acscatal.5b01409.

36. Wang, L.; Kodama, K.; Hirose, T. DBU/benzyl bromide: an efficient catalytic system for the chemical fixation of $\mathrm{CO}_{2}$ into cyclic carbonates under metal-and solvent-free conditions. Catal. Sci. Technol. 2016, 6, 3872-3877, DOI: 10.1039/c5cy01892g.

37. Wang, B.; Luo, Z.; Elageed, E. H.; Wu, S.; Zhang, Y.; Wu, X.; Xia, F.; Zhang, G.; Gao, G. DBU and DBU-Derived Ionic Liquid Synergistic Catalysts for the Conversion of Carbon Dioxide/Carbon Disulfide to 3-Aryl-2-oxazolidinones/[1, 3] Dithiolan-2-ylidenephenyl-amine. ChemCatChem 2016, 8, 830-838, DOI: 10.1002/cctc.201500928.

38. Chatelet, B.; Joucla, L.; Dutasta, J.-P.; Martinez, A.; Szeto, K. C.; Dufaud, V. Azaphosphatranes as structurally tunable organocatalysts for carbonate synthesis from $\mathrm{CO}_{2}$ and epoxides. J. Am. Chem. Soc. 2013, 135, 5348-5351, DOI: 10.1021/ja402053d.

39. Liu, M.; Liang, L.; Li, X.; Gao, X.; Sun, J. Novel urea derivative-based ionic liquids with dual-functions: $\mathrm{CO}_{2}$ capture and conversion under metal-and solvent-free conditions. Green Chem. 2016, 18 , 2851-2863, DOI: 10.1039/C5GC02605A.

40. Sopeña, S.; Martin, E.; Escudero-Adán, E. C.; Kleij, A. W. Pushing the Limits with Squaramide-Based Organocatalysts in Cyclic Carbonate Synthesis. ACS Catal. 2017, 7, 3532-3539, DOI: 10.1021/acscatal.7b00475.

41. Shen, Y. M.; Duan, W. L.; Shi, M. Phenol and Organic Bases Co-Catalyzed Chemical Fixation of Carbon Dioxide with Terminal Epoxides to Form Cyclic Carbonates. Adv. Synth. Catal. 2003, 345, 337-340, DOI: 10.1002/adsc.200390035.

42. Whiteoak, C. J.; Nova, A.; Maseras, F.; Kleij, A. W., Merging sustainability with organocatalysis in the formation of organic carbonates by using $\mathrm{CO}_{2}$ as a feedstock. ChemSusChem 2012, 5, 20322038, DOI: $10.1002 /$ cssc.201200255

43. Sopeña, S.; Fiorani, G.; Martín, C.; Kleij, A. W. Highly Efficient Organocatalyzed Conversion of Oxiranes and $\mathrm{CO}_{2}$ into Organic Carbonates. ChemSusChem 2015, 8, 3248-3254, DOI: 10.1002/cssc.201500710.

44. Büttner, H.; Steinbauer, J.; Wulf, C.; Dindaroglu, M.; Schmalz, H. G.; Werner, T. Organocatalyzed Synthesis of Oleochemical Carbonates from $\mathrm{CO}_{2}$ and Renewables. ChemSusChem 2017, 10, 1076-1079, DOI: $10.1002 / \mathrm{cssc} .201601163$.

45. Toda, Y.; Komiyama, Y.; Kikuchi, A.; Suga, H. Tetraarylphosphonium Salt-Catalyzed Carbon Dioxide Fixation at Atmospheric Pressure for the Synthesis of Cyclic Carbonates. ACS Catal. 2016, 6, 6906-6910, DOI: 10.1021/acscatal.6b02265.

46. Della Monica, F.; Buonerba, A.; Grassi, A.; Capacchione, C.; Milione, S. Glycidol: an Hydroxyl-Containing Epoxide Playing the Double Role of Substrate and Catalyst for $\mathrm{CO}_{2}$ Cycloaddition Reactions. ChemSusChem 2016, 9, 3457-3464, DOI: 10.1002/cssc.201601154.

47. Wilhelm, M. E.; Anthofer, M. H.; Cokoja, M.; Markovits, I. I.; Herrmann, W. A.; Kühn, F. E. Cycloaddition of carbon dioxide and epoxides using pentaerythritol and halides as dual catalyst system. ChemSusChem 2014, 7, 1357-1360, DOI: 10.1002/cssc.201301273.

48. Kaneko, S.; Shirakawa, S. Potassium Iodide-Tetraethylene Glycol Complex as a Practical Catalyst for $\mathrm{CO}_{2}$ Fixation Reactions with Epoxides under Mild Conditions. ACS Sustainable Chem. Eng. 2017, 5, 2836-2840, DOI: 10.1021/acssuschemeng.7b00324.

49. Sun, J.; Cheng, W.; Yang, Z.; Wang, J.; Xu, T.; Xin, J.; Zhang, S. Superbase/cellulose: an environmentally benign catalyst for chemical fixation of carbon dioxide into cyclic carbonates. Green Chem. 2014, 16, 3071-3078, DOI: 10.1039/C3GC41850B.

50. Büttner, H.; Lau, K.; Spannenberg, A.; Werner, T. Bifunctional One-Component Catalysts for the Addition of Carbon Dioxide to Epoxides. ChemCatChem 2015, 7, 459-467, DOI: $10.1002 /$ cctc. 201402816 .

51. Saptal, V. B.; Bhanage, B. M. Bifunctional Ionic Liquids Derived from Biorenewable Sources as Sustainable Catalysts for Fixation of Carbon Dioxide. ChemSusChem 2017, 10, 1145-1151, DOI: $10.1002 /$ cssc. 201601228.

52. Büttner, H.; Steinbauer, J.; Werner, T. Synthesis of Cyclic Carbonates from Epoxides and Carbon Dioxide by Using Bifunctional One-Component Phosphorus-Based Organocatalysts. ChemSusChem 2015, 8, 2655-2669, DOI: $10.1002 /$ cssc.201500612.

53. Gennen, S.; Alves, M.; Méreau, R.; Tassaing, T.; Gilbert, B.; Detrembleur, C.; Jerome, C.; Grignard, B. Fluorinated Alcohols as Activators for the Solvent-Free Chemical Fixation of Carbon Dioxide into Epoxides. ChemSusChem 2015, 8, 1845-1849, DOI: $10.1002 /$ cssc. 201500103 .

54. Anthofer, M. H.; Wilhelm, M. E.; Cokoja, M.; Drees, M.; Herrmann, W. A.; Kühn, F. E. Hydroxy-Functionalized Imidazolium Bromides as Catalysts for the Cycloaddition of $\mathrm{CO} 2$ and Epoxides to Cyclic Carbonates. ChemCatChem 2015, 7, 94-98, DOI: $10.1002 /$ cctc. 201402754 .

55. Wang, L.; Zhang, G.; Kodama, K.; Hirose, T. An efficient metal-and solvent-free organocatalytic system for chemical fixation of $\mathrm{CO}_{2}$ into cyclic carbonates under mild conditions. Green Chem. 2016, 18, 1229-1233, DOI: 10.1039/C5GC02697K.

56. Hardman-Baldwin, A. M.; Mattson, A. E. Silanediol-Catalyzed Carbon Dioxide Fixation. ChemSusChem 2014, 7, 3275-3278, DOI: $10.1002 / \mathrm{cssc} .201402783$.

57. Wang, J.; Zhang, Y., Boronic Acids as Hydrogen Bond Donor Catalysts for Efficient Conversion of $\mathrm{CO}_{2}$ into Organic Carbonate in Water. ACS Catal. 2016, 6, 4871-4876, DOI 10.1021/acscatal.6b01422.

58. Shadnia, H.; Wright, J. S. Understanding the Toxicity of Phenols: Using Quantitative Structure-Activity Relationship and Enthalpy Changes To Discriminate between Possible Mechanisms. Chem. Res. Toxicol. 2008, 21, 1197-1204., DOI: 10.1021/tx800058r.

59. Xiong, J.; Wang, Y.; Xue, Q.; Wu, X. Synthesis of highly stable dispersions of nanosized copper particles using L-ascorbic acid. Green Chem. 2011, 13, 900-904, DOI: 10.1039/C0GC00772B.

60. Liang, S.; Liu, H.; Jiang, T.; Song, J.; Yang, G.; Han, B. Highly efficient synthesis of cyclic carbonates from $\mathrm{CO}_{2}$ and epoxides over cellulose/KI. Chem. Commun. 2011, 47, 2131-2133, DOI: 10.1039/C0CC04829A.

61. Liu, X.-F.; Song, Q.-W.; Zhang, S.; He, L.-N. Hydrogen bonding-inspired organocatalysts for $\mathrm{CO}_{2}$ fixation with epoxides to cyclic carbonates. Catal. Today 2016, 263, 69-74, DOI: 10.1016/j.cattod.2015.08.062.

62. Pappenberger, G.; Hohmann, H.-P., Industrial production of L-ascorbic acid (Vitamin C) and D-isoascorbic acid. In Biotechnology of Food and Feed Additives, Springer Verlag Berlin Heidelberg: 2013; pp 143-188, DOI: 10.1007/10_2013_243.

63. Kelly, M. J.; Barthel, A.; Maheu, C.; Sodpiban, O.; Dega, F.-B.; Vummaleti, S. V. C.; Abou-Hamad, E.; Pelletier, J. D. A.; Cavallo, L.; D'Elia, V.; Basset, J.-M. Conversion of actual flue gas CO 2 via cycloaddition to propylene oxide catalyzed by a single-site, recyclable zirconium catalyst. J. CO2 Util. 2017, 20, 243-252, DOI: 10.1016/j.jcou.2017.05.020.

64. D'Elia, V.; Ghani, A. A.; Monassier, A.; Sofack-Kreutzer, J.; Pelletier, J. D. A.; Drees, M.; Vummaleti, S. V. C.; Poater, A.; Cavallo, L.; Cokoja, M.; Basset, J.-M.; Kühn, F. E. Dynamics of the $\mathrm{NbCl}_{5}-\mathrm{Cat}-$ alyzed Cycloaddition of Propylene Oxide and $\mathrm{CO}_{2}$ : Assessing the Dual Role of the Nucleophilic Co-Catalysts. Chem. Eur. J. 2014, 20, 1187011882, DOI: 10.1002/chem.201400324.

65. Akiyama, T.; Mori, K. Stronger Brønsted acids: recent progress. Chemical Rev. 2015, 115, 9277-9306, DOI: 10.1021/acs.chemrev.5b00041. 


\section{For Table of Contents Use Only}

2

3

4

5

6

7

8

9

10

11

12

13

14

15

16

17

18

19

20

21

22

23

24

25

26

27

28

29

30

31

32

33

34

35

36

37

38

39

40

41

42

43

44

45

46

47

48

49

50

51

52

53

54

55

56

57

58

59

60

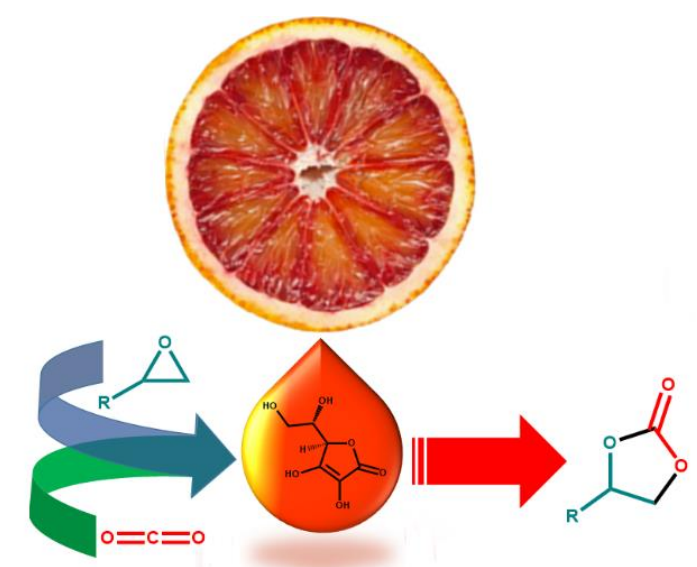

Ascorbic acid is a sustainable and bifunctional hydrogen bond donor for the conversion of $\mathrm{CO}_{2}$ to carbonates under ambient conditions. 


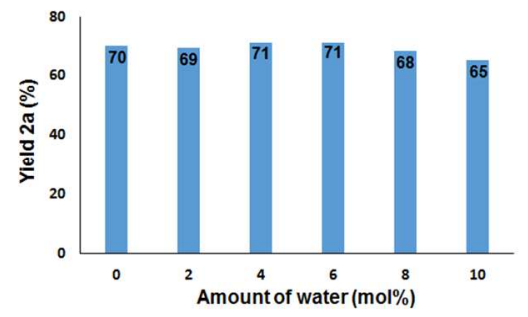

Figure 1. Catalytic performance of ascorbic acid ( $2 \mathrm{~mol} \%)$ and TBAI (4 mol\%) in the cycloaddition of $\mathrm{CO} 2$ to epichlorhydrin in the presence of increasing amounts water at r.t., 1 bar $\mathrm{CO} 2$ (balloon), $23 \mathrm{~h}$.

\section{$338 \times 190 \mathrm{~mm}(96 \times 96 \mathrm{DPI})$}




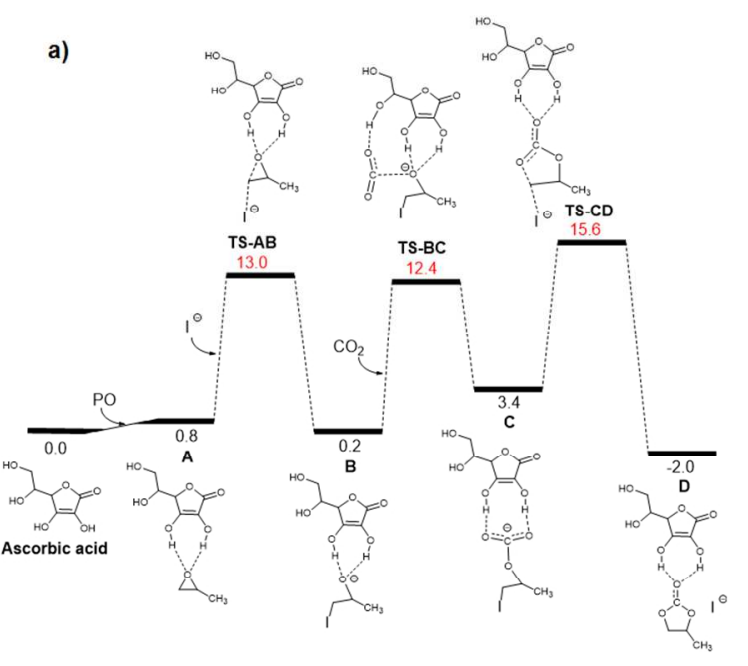

Figure 2. a) Computed free energy surface for the cycloaddition of $\mathrm{CO} 2$ to $\mathrm{PO}$ catalyzed by ascorbic acid. Free energies in solution (PO as the solvent) are given in $\mathrm{kcal} / \mathrm{mol}$ relative to the starting point. The values in red represent the energies of the transition states.

$$
270 \times 152 \mathrm{~mm}(120 \times 120 \mathrm{DPI})
$$


b)

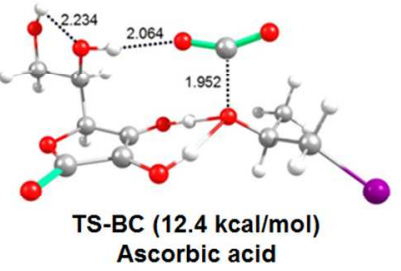

c)

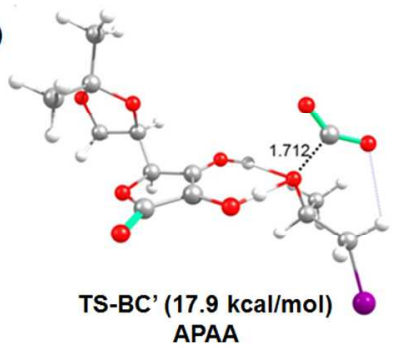

b) Geometries of the $\mathrm{CO} 2$ insertion transition states, TS-BC, for ascorbic acid and (c) TS-BC' for the APAA derivative.

$270 \times 152 \mathrm{~mm}(120 \times 120 \mathrm{DPI})$ 


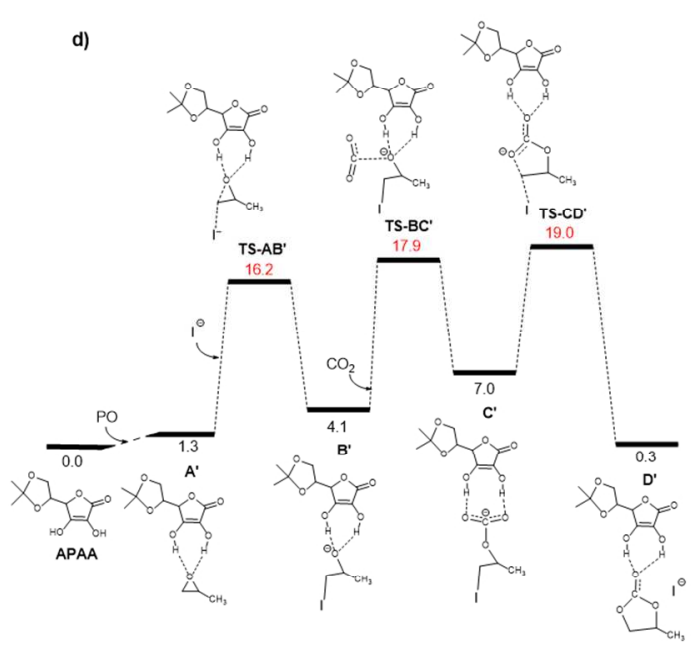

\section{free energy surface for the cycloaddition of $\mathrm{CO} 2$ to $\mathrm{PO}$ catalyzed} by APAA. Selected distances are given in $\AA$.

$338 \times 190 \mathrm{~mm}(96 \times 96 \mathrm{DPI})$ 

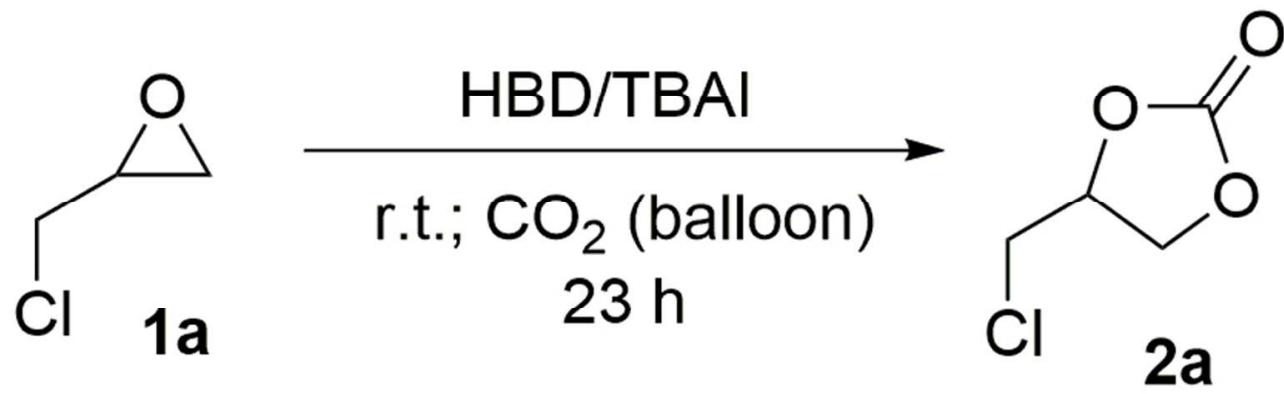

\author{
Scheme for Table 1 \\ $71 \times 23 \mathrm{~mm}(300 \times 300$ DPI $)$
}




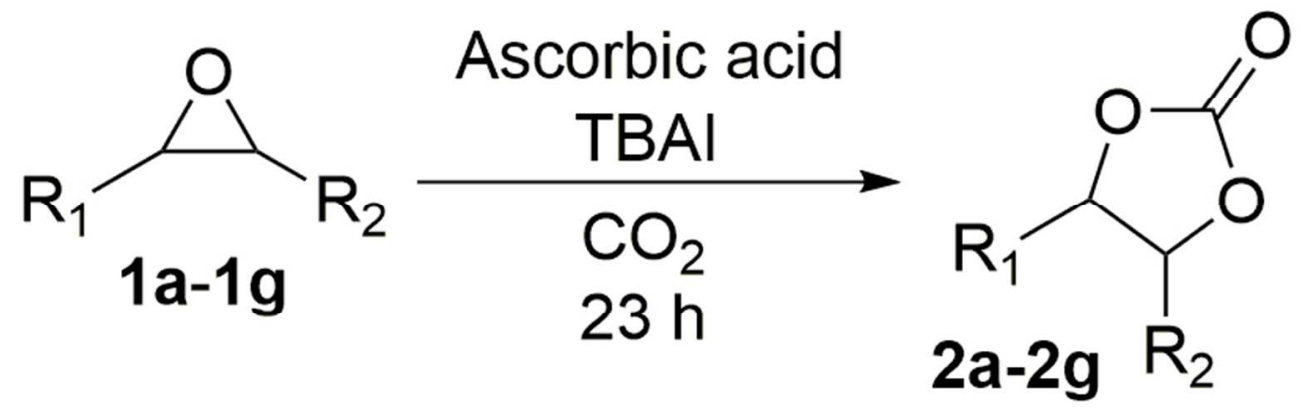

Scheme for Table 2

$70 \times 23 \mathrm{~mm}(300 \times 300$ DPI $)$ 


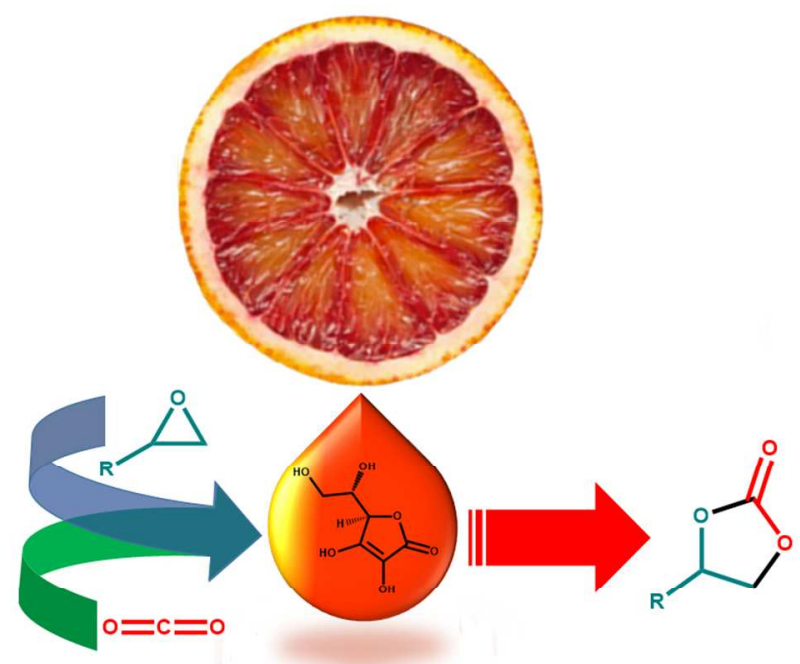

Graphical abstract

$270 \times 152 \mathrm{~mm}(120 \times 120 \mathrm{DPI})$ 